\title{
Cooperation between universities and primary \& secondary schools --Investigation on Teachers' Participation
}

\author{
Liu Jialong; Zhang Yuandong, Wang Yuanming \\ Leshan Normal University, Leshan, Sichuan, 614000
}

\begin{abstract}
The Cooperation between universities and primary \& secondary schools is one of the hot issues in the current educational theory and practice research. The university education teaching theory as the main research institutions, to provide intellectual support and an important theoretical guidance for the reform and development of basic education; primary and middle schools as a first-line teaching practice, but also provides a valuable test and practical experience to carry out theoretical research of education and teaching of higher education. This survey aims to understand the current situation of teachers' participation in the university and school collaboration process, through a series of investigations and interviews, participation and cooperation of teachers to grasp the current problems and shortcomings, to provide the necessary foundation and guidance for the construction of university teachers and teachers of primary and secondary school network learning community.
\end{abstract}

Keywords: Cooperation ; universities ; Teachers' Participation

Author Introduction: Liu Jialong(1983 -), male, Tongyu Jilin, assistant researcher, master, engaged in education management..Tel: 15283350212.E-mail:

464748895@qq.com. Zhang Yuandong (1972-) male, jingyan Sichuan, Associate Research Fellow, master, engaged in education management. Wang Yuanming (1976-) male, nanjiang Sichuan, lecturer, master, reform in education. 


\section{The Purpose Of The Investigation}

This survey is the key research base of Humanities and Social Sciences in Colleges and universities in Sichuan Province -- Sichuan primary and secondary school teachers' Professional Development Research Center project "community universities and research cooperation in primary and secondary school teachers based on" learning network (PDTR2013-018) to carry out in 2013. The Cooperation between universities and primary \& secondary schools is one of the hot issues in the current educational theory and practice research. The university education teaching theory as the main research institutions, to provide intellectual support and an important theoretical guidance for the reform and development of basic education; primary and middle schools as a first-line teaching practice, but also provides a valuable test and practical experience to carry out theoretical research of education and teaching of higher education. This survey aims to understand the current situation of teachers' participation in the university and school collaboration process, through a series of investigations and interviews, participation and cooperation of teachers to grasp the current problems and shortcomings, to provide the necessary foundation and guidance for the construction of university teachers and teachers of primary and secondary school network learning community.

\section{Survey Methods}

This study used a combination of qualitative research and quantitative research. First of all, using the method of questionnaire survey in Shizhong District of Leshan city four primary school (primary school, Xu Jiabian primary school, foreign language school, experimental primary school musicians) and two secondary schools (experimental middle school in Leshan, cottage high school) were randomly sampled, a total of 120 questionnaires, 115 questionnaires, 110 valid questionnaires, the questionnaire is invalid in 5, the effective recovery rate was $91.67 \%$. This questionnaire has 18 questions, which relate to the attitude, motivation and goal, the way and content, the role and the effect of cooperation between University and primary and secondary schools. At the same time, the interview method was used to understand the relevant issues involved in the study.

\section{The Results of The Survey}

From the overall survey, the secondary school teachers and college teachers are relatively more cooperative, and the cooperation between primary school teachers and university teachers is relatively small. Among them, $76 \%$ of middle school teachers think that there are many opportunities to participate in university research cooperation projects, and only $52 \%$ of primary school teachers believe 
that there are opportunities to participate in the university teaching and research projects. The main reason is the teaching content of primary school is easy, and the close degree of higher education with relatively low, and the knowledge of middle school involves a broader, both from the teachers' professional development, or the actual needs of teaching, middle school teachers and university teachers are more closely linked. From the point of view of the type involved in the project, there are $72 \%$ cooperation projects of teachers are teaching probation and practice, there are $15 \%$ teachers involved in the teaching reform project, $8 \%$ of the teachers participate in the research project, $5 \%$ of the teachers involved in the contest.

Primary and secondary school teachers to university and primary and secondary school cooperation attitude, mainly from the teacher's view of cooperation, motivation and objectives of the three dimensions to carry on the investigation. $21 \%$ of the teachers think that the participation of University School Cooperation Project on the development of the school is very helpful, $65 \%$ of teachers think that the participation of university school cooperation projects for their professional development is very helpful, $14 \%$ of teachers think that the participation of university school cooperation project is mainly to help university teachers to complete teaching task. From the motivation and goal of middle and primary school teachers to participate in University and primary and secondary school cooperative projects (see Table 1 and table two), mainly focus on their own professional development.

Table 1: the motivation of participating universities and primary and secondary school cooperative projects

\begin{tabular}{|c|c|c|c|c|}
\hline \multicolumn{2}{|c|}{ Administrative tasks } & School development & \multirow[t]{2}{*}{ Competitive } & \multirow[t]{2}{*}{ pressure } \\
\hline Profession & ment $\quad$ T & & & \\
\hline Number & 25 & \multirow[t]{2}{*}{5} & \multicolumn{2}{|r|}{35} \\
\hline 45 & 110 & & \multirow{3}{*}{\multicolumn{2}{|c|}{31.8}} \\
\hline Proportion & 22.7 & \multirow[t]{2}{*}{4.5} & & \\
\hline 41 & 100 & & & \\
\hline \multicolumn{5}{|c|}{$\begin{array}{l}\text { Table 2: the goal of participating universities and primary and secondary } \\
\text { school cooperative projects }\end{array}$} \\
\hline \multicolumn{2}{|c|}{ Professional development } & Professional title appraisal & Value realization & Obtain \\
\hline Number & 38 & 31 & & 17 \\
\hline 24 & 110 & & & \\
\hline Proportion & 34.5 & 28.2 & & 15.5 \\
\hline 21.8 & 00 & & & \\
\hline
\end{tabular}

Primary and secondary school teachers to participate in University and primary and secondary school cooperation mode and state, mainly from six aspects to study. There are $28.2 \%$ forms of cooperation by the University Teachers' lectures, discussion of teachers listening in primary and secondary schools, there are $41.8 \%$ forms of cooperation is composed of primary and secondary school teachers award course, followed by University Teachers' comments, there are $14.5 \%$ forms of cooperation is the division of university teachers and teachers to carry out research, there are $15.5 \%$ cooperation is based 
on the network communication platform in the form of to study (see table three). The primary and middle school teachers tend to be able to work together with the way of study and discussion. When the university teachers in the absence of problems of only $36 \%$ teachers in primary and middle school through the telephone network or consult the university teachers, and more is through self check information and consulting peers or search the Internet to solve the problem. In the process of cooperation, there are $4 \%$ teachers to the organizer itself, leading cooperative study, $48 \%$ of the teachers to actively participate in the discussion, there are $28 \%$ teachers to show their point of view, there are $20 \%$ teachers in the spectator's attitude in the process of cooperation, hardly speak. In the process of cooperation, the $75 \%$ primary and secondary school teachers is to learn by itself, and the cooperation and assistance and a smaller proportion of onlookers. In the process of cooperation, the university teachers and the teachers disagree, there are $48 \%$ primary and secondary school teachers will put forward their own views and discuss the selection of university teachers, primary and secondary school teachers in $24 \%$ will choose a recognized university teacher's point of view while retaining their point of view, there are $16 \%$ primary and secondary school teachers will obey university teachers point of view, only $12 \%$ of the teachers in primary and middle school will stick to their point of view right.

Table 3: primary and secondary school teachers to participate in the way of cooperation between universities and primary and secondary schools

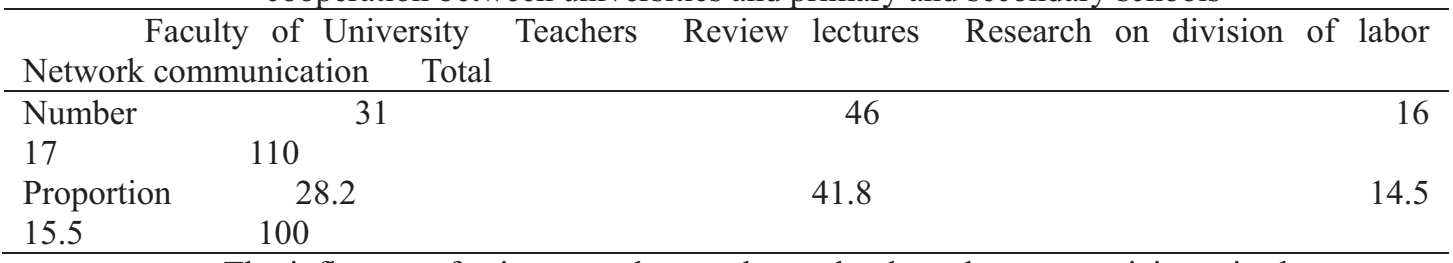

The influence of primary and secondary school teachers to participate in the University and primary and secondary school cooperation effect, mainly from the four dimensions of the investigation. From the psychological state is concerned, there are $62 \%$ primary and secondary school teachers think research and cooperation between primary and secondary schools in the university to improve the teaching level, $23 \%$ of the teachers think that want to participate in but their research level is limited, there are $10 \%$ teachers in primary and secondary schools that participated in the study is an important part of education career, teachers only $5 \%$ that good teaching is more important than to participate in the study. From the school perspective, in the study of primary and secondary school teachers' task $65 \%$ is mutually agreed by the school and university teachers, there are $22 \%$ schools by decision $13 \%$, is advocated by university teachers, but the teachers almost no participation in decision-making. In the process of cooperation, and actively participate in the cause of failed to primary and secondary schools, $56 \%$ of teachers think that their study is limited, $25 \%$ of the teachers think it is to study, $8 \%$ of the teachers are forced to participate in the administrative requirements, $11 \%$ of the teachers have the opportunity to participate. In the course of the study, the primary and secondary school teachers 
think that the most important is to study the process of university teachers to give help and guidance (see table four).

Table 4: the most important in the process of the study of teachers' participation in primary and secondary schools

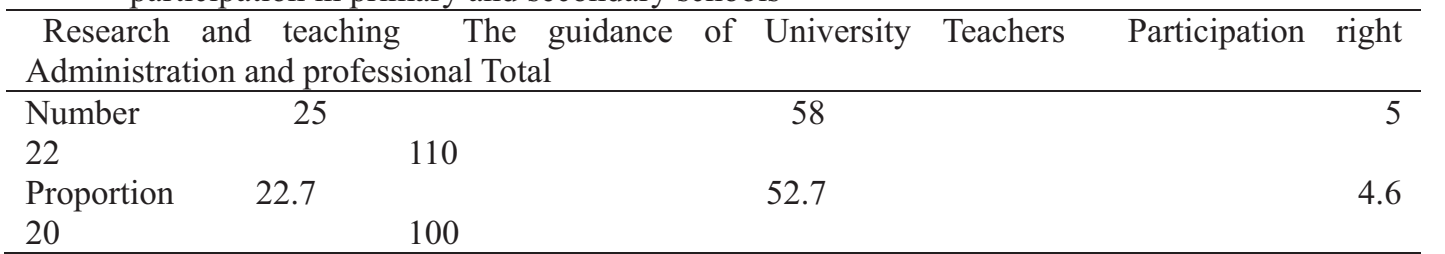

Primary and secondary school teachers to participate in the study of the effects and promoting factors, mainly from three aspects. First of all, to participate in collaborative research in primary and middle school teachers, the biggest gain is $45 \%$ of the teachers think that teaching ability improved, $47 \%$ of teachers think that their study ability improved, only the following part that there is not much change myself. Secondly, in cooperation in the course of the study, $17 \%$ of the teachers think well harmonize the relationship of teaching and research can not, $24 \%$ of the teachers think that when the conflict between teaching and research, teaching priority, $22 \%$ of the teachers think that in the event of a conflict between teaching and research, scientific research priorities, $27 \%$ of teachers think that if the school can give more incentive, will be more actively involved in research. Finally, the primary and secondary school teachers think that the most able to stimulate their participation in the University and primary and secondary school cooperative research is to improve research grants and reduce the corresponding class (see table five).

Table 5: the factors of promoting the study of teachers' participation in primary and middle schools

\begin{tabular}{|c|c|c|c|}
\hline \multicolumn{2}{|c|}{$\begin{array}{l}\text { Reduce the amount of hours } \\
\text { Promotion opportunities Total }\end{array}$} & Improve research grants & Increase training opportunities \\
\hline Number & 35 & 36 & 15 \\
\hline 24 & 110 & & \\
\hline $\begin{array}{l}\text { Proportion } \\
21.8\end{array}$ & $100 \quad 31.8$ & 32.7 & 13.7 \\
\hline
\end{tabular}

From the results of the survey, primary and secondary school teachers' willingness to participate in the study of University and primary and secondary schools is still relatively strong, especially in order to meet their own professional development of teachers. However, in the process of cooperation in reality we also found that due to space, driven by the interests and influence of external administration, university teachers and teachers' cooperation often showing discontinuous characteristics, utilitarian, formalized and inefficient, to some extent limit the depth and validity and quality cooperation between the two. In order to avoid these adverse effects, it is necessary to construct a new cooperative model. The teacher learning community is able to lift the limit of time and space to a great extent, to the network as a platform for the exchange of teachers in primary and middle schools can alleviate the tension and inferiority, to peace, equality, relaxed state to participate in the study of communication, so as to 
enhance the quality and level of cooperation.

From the school, primary and secondary school teachers and university teachers to strengthen the cooperation between both the overall quality of teachers and to enhance the level of sustainable development, and can obtain more external resources to promote the school. From the survey, in the University School collaborative research relatively few opportunities for primary and secondary school teachers, including teachers' research level limit, and school administrative arrangements, class work, to a certain extent, the effect of the frequency and efficiency of teachers in primary and middle school teachers and University cooperation. Therefore, primary and secondary schools to enhance the leadership "to promote the cooperation of teachers" management awareness, to create a democratic and harmonious teacher cooperative culture to the teachers' cooperation and exchange platform to build a modern comprehensive application ", to improve the mechanism of teachers' cooperation to protect the legitimate perfectly logical and reasonable.

Through interviews, we understand the wishes of the exchange and cooperation between teachers and college teachers in primary and secondary schools and suggestions. At the same time, university teachers and primary and secondary school teachers are more interested in the network learning community, and think that this kind of form can largely alleviate the problems and deficiencies of traditional cooperative communication. But at the same time, teachers are also more worried about how to construct such a platform, how to manage, how to protect the intellectual property rights and other issues. These issues are the focus and difficulty of our research. Our initial assumption is that we can build the teachers' network learning community based on the University Teachers' development center and the primary and secondary schools alliance. Operation funds can be funded through projects, social support and other forms. Ensure the legitimacy and rationality of cooperation through explicit rules and regulations.

\section{Reference:}

[1]Wu Kangning. From the interests of the joint to the cultural integration: Toward the University and the middle and primary schools of the depth of cooperation[J]. Journal of Nanjing Normal University (Social Science),2010.(03) [2] Peng Hongbin, Yuanhuifang. Cooperation between universities and primary and secondary schools: Predicament, cause and countermeasure $[\mathrm{J}]$. Journal of Jimei University,2011(02) 